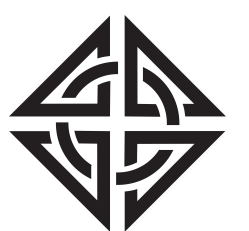

SCIENTIA

I RAN I CA
Sharif University of Technology

Scientia Iranica

Transactions A: Civil Engineering

http://scientiairanica.sharif.edu

\title{
Estimating the response of concrete moment frames subjected to individual ground motions using endurance time excitation functions fitted to average acceleration response spectra
}

\author{
S. Davari* and H.E. Estekanchi
}

Department of Civil Engineering, Sharif University of Technology, Tehran, Iran.

Received 15 March 2020; received in revised form 21 April 2021; accepted 5 July 2021

\author{
KEYWORDS \\ Endurance time \\ method; \\ Time history analysis; \\ Estimation of the \\ accuracy; \\ Endurance time \\ excitation functions; \\ Estimation of \\ structural responses.
}

\begin{abstract}
Endurance Time (ET) method is an efficient time history-based analysis procedure that applies special acceleration functions for estimating the seismic performance of structures at different excitation levels in every single analysis. For some structures with complex models, such as dams, it is impractical to conduct multiple seismic analyses due to the high computational cost. In such cases, for obtaining accurate structural responses, it is recommended that researchers pay conscious attention to choose compatible Endurance Time Excitation Functions (ETEFs) regarding the basic properties of their structures, such as the soil type of the site, the selected design spectrum, and the type of the analysis. However, in this study, it is observed that using various ETEFs to analyze a concrete moment frame subjected to a single earthquake ground motion will cause us to obtain unreliable responses. In other words, different ETEF series have significantly different accuracies (26\% error) in predicting the responses of the mentioned structure which is subjected to individual earthquake ground motions. This problem is mainly caused by the turbulent nature of a single ground motion spectrum, which is in contrast to the smooth shape of the ETEF spectrum. One solution to avoid this problem could be to produce a specific ETEF.

(C) 2021 Sharif University of Technology. All rights reserved.
\end{abstract}

\section{Introduction}

Time history analysis can generate different results for a specific structure subjected to different ground motions. This difference occurs because no two seismic ground motions have the same records. To observe the behavior of the structure under the action of an earthquake, a large number of seismic records must

\footnotetext{
*. Corresponding author.

E-mail addresses: sinadavari1376@yahoo.com (S. Davari); stkanchi@sharif.edu (H.E.Estekanchi)
}

doi: $10.24200 /$ sci.2021.55649.4331 be selected and utilized. However, the Endurance Time (ET) method can provide a proper setting for this observation by a single ET analysis. In other words, a single ET analysis is equivalent to analyzing earthquakes of all intensities [1].

Several series of Endurance Time Excitation Functions (ETEFs) have been generated so that they could match the target acceleration spectrum (code design spectrum or spectrum produced by the ground motions) whereas the duration consistency has not been directly considered [2]. Although several tables containing the basic attributes of each ETEF series are provided in the references, unfortunately, for most of the research, researchers select the most recently 
produced series or a random one, ignoring these tables and the attributes of their projects. In this study, it is proved that various series of ETEFs have significantly different accuracies in predicting the responses of structures subjected to the earthquake ground motions.

There are several types of structures on which it is impractical to perform multiple time history analyses because of the tremendous computational cost or other limitations. A great example is dam structures. In analyzing such cases, specific ET records should be chosen or produced that are compatible with the basic properties of the project. In such large models, a large number of errors are unacceptable, and using the appropriate ETEF series to analyze the system again will waste a lot of time and effort. Shaking table tests, especially full-scale tests, also have conditions that make it impractical to perform multiple analyses.

The structure studied is an eight-story concrete moment resisting frame (three floors underground) located in Tehran. The geometrical information of the structure is shown in Figure 1.

The analysis and design procedures of the structure are in agreement with the Iranian National Building Code standard 2800 and ASCE7-10. It is assumed that the shear wave velocity of the site where the structure is located is $425 \mathrm{~m} / \mathrm{s}$. In other words, in agreement with Refs. [3,4], the C-type soil and type II are selected, respectively. The total weight and lateral stiffness of the structure were equal to $7,416.71$ ton $_{f}$ and $212.42 \operatorname{ton}_{f} / \mathrm{cm}$ respectively, and the fundamental vibration period of the structure was equal to 1.18 seconds. The mass participation ratio of the dominant mode of vibration (first mode) was equal to $57.7 \%$. The damping ratio of the system is assumed to be 0.05 . The structure is classified as risk category II or medium importance according to Refs. [3] and [4], respectively, and the design base shear is equal to 976 ton $_{f}$ [4].

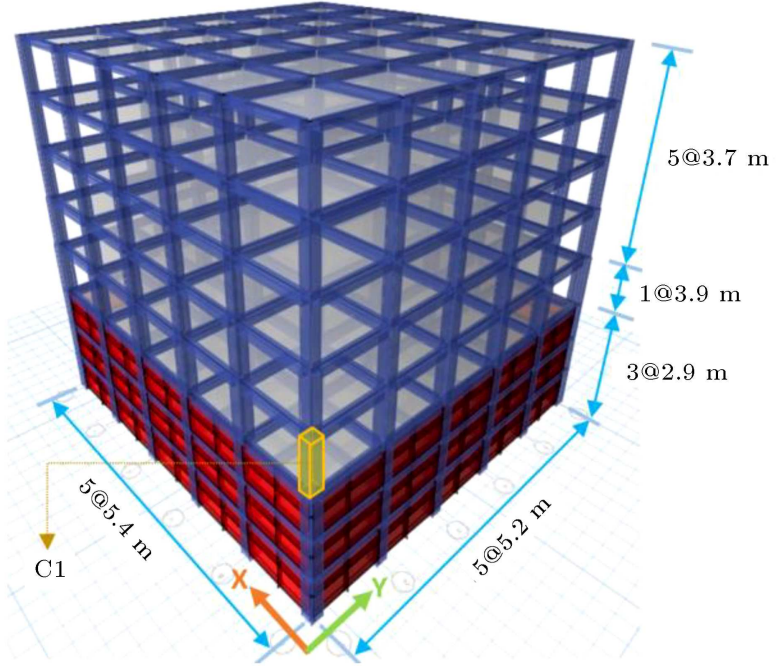

Figure 1. General view of the studied structure.
In this study, to compare the responses of different series of ETEF and earthquakes, the following parameters are randomly selected. The studied structure subjected to the mentioned records is analyzed, and the response time histories of these parameters are determined. The so-called "control parameters" are as follows:

1. Base shear in $\mathrm{X}$ direction;

2. Roof displacement in $\mathrm{X}$ direction;

3. Axial force of column $\mathrm{C} 1$ at story 1 (C1 is marked in Figure 1).

In the present study, an engineering software suitable for the analysis and design of multi-story buildings has been utilized for analyzing the structure [5]. The three-dimensional model of the structure under study is analyzed in a single direction ( $\mathrm{X}$ direction) without considering the effects of torsion. The type of analysis is nonlinear modal analysis assuming that the material used has perfect elastic-plastic behavior.

\section{Reference ground motions set}

The first horizontal component of the 22 far-field records, proposed by FEMA P-695, has been utilized in this study, and the two components recorded in other directions are ignored. These ground motions are applicable to structures located on soil type $\mathrm{C}$ [6]. Table 1 shows the description of the selected ground motions used in this study, and Figure 2 shows their unscaled response acceleration spectra. It should be noted that all records are obtained from the Pacific Earthquake Engineering Research Center (PEER) ground motion database. For the sake of simplification, the selected ground motions are applied to the studied structure merely in its $\mathrm{X}$ direction. Due to the concentricity of

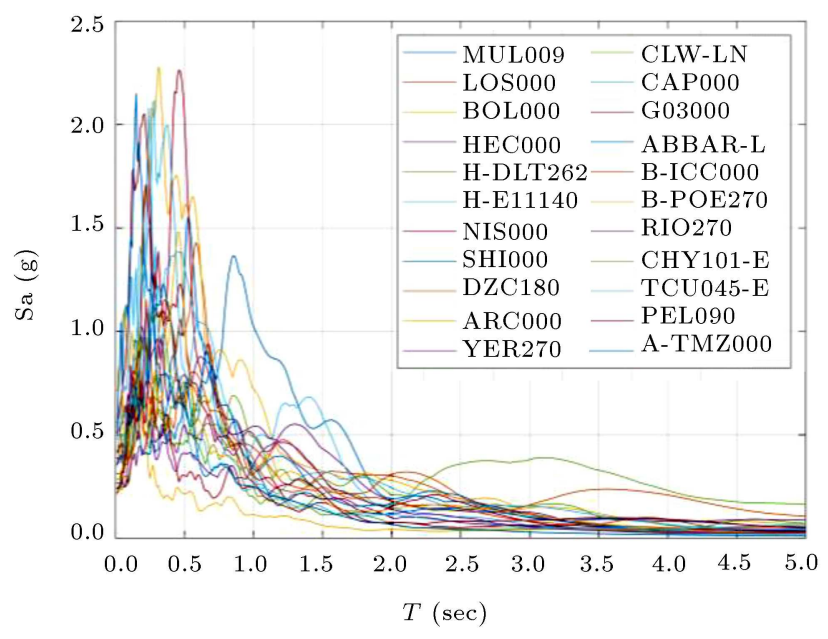

Figure 2. Unscaled response acceleration spectra of the selected ground motions. 
Table 1. Description of the selected ground motions [6,7].

\begin{tabular}{cccccc}
\hline ID no. & Recorded seq. no. & $\begin{array}{c}\text { Lowest freq. } \\
(\mathbf{H z})\end{array}$ & File name & $\begin{array}{c}\text { PGA }_{\text {max }} \\
(\mathbf{g})\end{array}$ & $\begin{array}{c}\text { PGV }_{\text {max }} \\
(\mathbf{c m} / \mathbf{s})\end{array}$ \\
\hline 1 & 953 & 0.25 & NORTHR/MUL009 & 0.52 & 63 \\
2 & 960 & 0.13 & NORTHR/LOS000 & 0.48 & 45 \\
3 & 1602 & 0.06 & DUZCE/BOL000 & 0.82 & 62 \\
4 & 1787 & 0.04 & HECTOR/HEC000 & 0.34 & 42 \\
5 & 169 & 0.06 & IMPVALL/H-DLT262 & 0.35 & 33 \\
6 & 174 & 0.25 & IMPVALL/H-E11140 & 0.38 & 42 \\
7 & 1111 & 0.13 & KOBE/NIS000 & 0.51 & 37 \\
8 & 1116 & 0.13 & KOBE/SHI000 & 0.24 & 38 \\
9 & 1158 & 0.24 & KOCAELI/DZC180 & 0.36 & 59 \\
10 & 1148 & 0.09 & KOCAELI/ARC000 & 0.22 & 40 \\
11 & 900 & 0.07 & LANDERS/YER270 & 0.24 & 52 \\
12 & 848 & 0.13 & LANDERS/CLW-LN & 0.42 & 42 \\
13 & 752 & 0.13 & LOMAP/CAP000 & 0.53 & 35 \\
14 & 767 & 0.13 & LOMAP/G03000 & 0.56 & 45 \\
15 & 1633 & 0.13 & MANJIL/ABBAR-L & 0.51 & 54 \\
16 & 721 & 0.13 & SUPERST/B-ICC000 & 0.36 & 46 \\
17 & 725 & 0.25 & SUPERST/B-POE270 & 0.45 & 36 \\
18 & 829 & 0.07 & CAPEMEND/RIO270 & 0.55 & 44 \\
19 & 1244 & 0.05 & CHICHI/CHY101-E & 0.44 & 115 \\
20 & 1485 & 0.05 & CHICHI/TCU045-E & 0.51 & 39 \\
21 & 68 & 0.25 & SFERN/PEL090 & 0.21 & 19 \\
22 & 125 & 0.13 & FRIULI/A-TMZ000 & 0.35 & 31 \\
\hline
\end{tabular}

centers of mass and stiffness of the studied structure, the effects of torsion are neglected.

To perform the dynamic analysis, the ground motions should be scaled. The scaling approach of the 16th chapter of ASCE7-10 is utilized in this study. The design spectrum of ASCE7 should be initially determined. Ref. [8] has provided the required parameters for Tehran city. Figure 3 shows the design response spectrum of the studied structure.

ASCE7 introduced the procedure of scaling seismic ground motions, which will be briefly explained below. The selected earthquake ground motions shall be scaled such that in the period range from $0.2 T$ to $1.5 T$, where $T$ is the fundamental period of the structure, the values of the earthquake acceleration spectra do not fall below the corresponding ordinate of the design response spectrum [3,9]. The flowchart indicated in Figure 4 provides a general view of the scaling procedure. Figures 5 and 6 provide a general view of the scaling procedure of this study.

As can be seen in Figure 6, the unscaled acceleration spectrum of the earthquakes needs to be multiplied by 1.64 to stand above the design spectrum in the determined period range. Therefore, all ground motions should be multiplied by 1.64 before being defined in the engineering software to meet the requirements of the selected design codes.

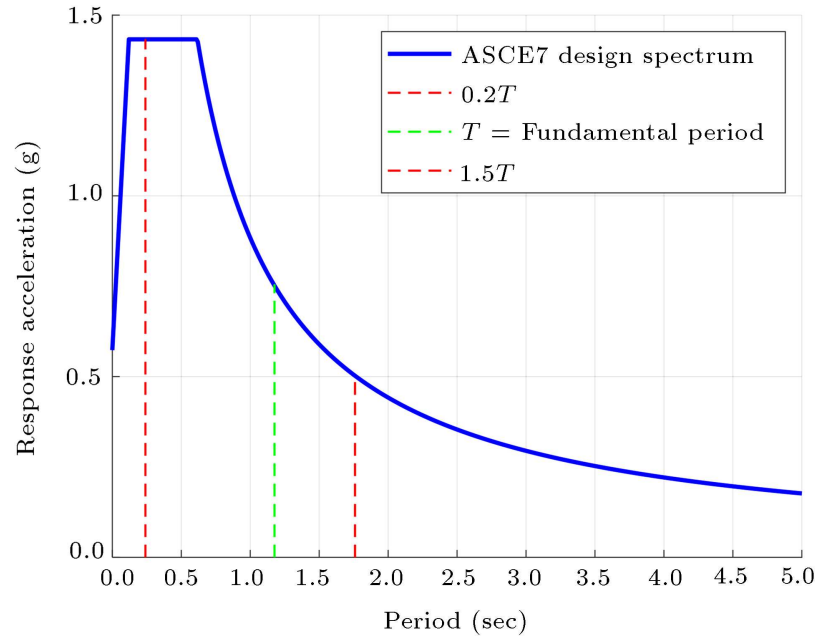

Figure 3. ASCE7 design spectrum for the studied structure $[3,8]$.

\section{Selected series of ETEFs}

The ETEFs are designed in such a way that their intensity increases over time. The excitation starts from the minimum intensity and gradually increases over time until the structure collapses. Utilizing these functions provides a proper setting for observing the structural responses through the entire range of 

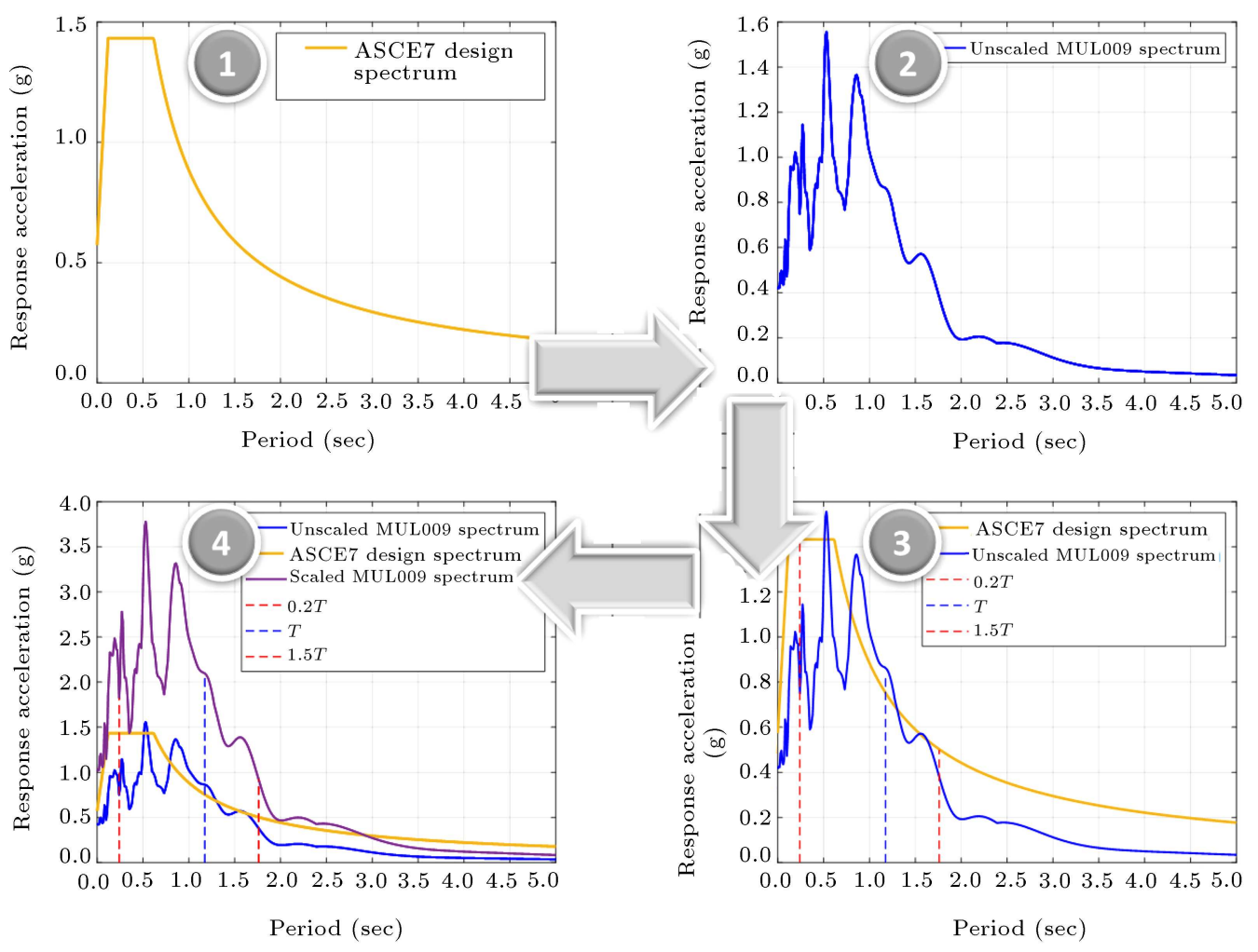

Figure 4. Flowchart indicting the procedure of scaling a single earthquake record.

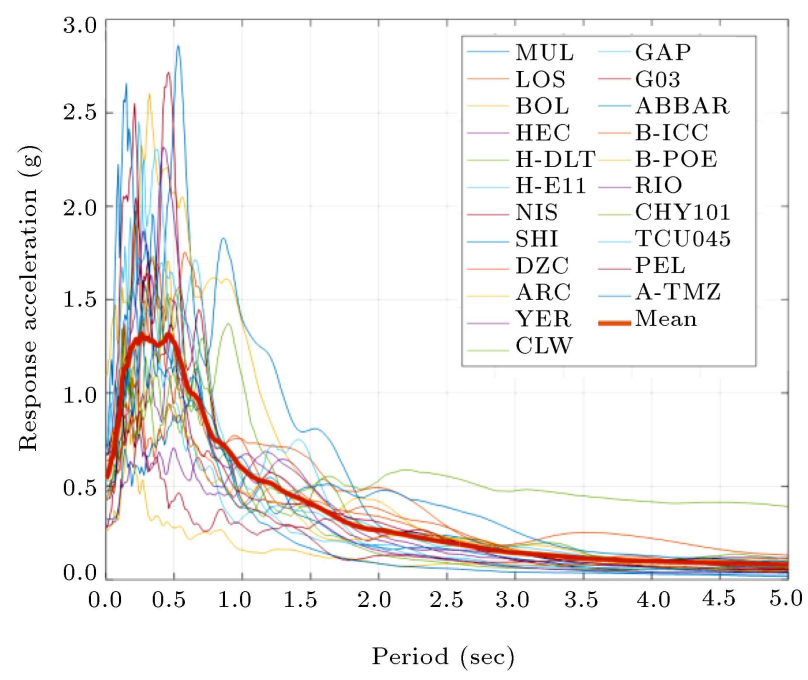

Figure 5. Unscaled spectra of the selected ground motions and their average.

intensities. Therefore, this method reduces the number of required time-history analyses. ETEFs are produced using numerical optimization methods in such a way that their acceleration response spectrum until any specific time is proportional to the intended design acceleration spectrum $[10,11]$. In this study, four series of ETEFs suitable for structures located on C-type soil structures are randomly selected. When the structure is subjected to 3 single records for each series, the time

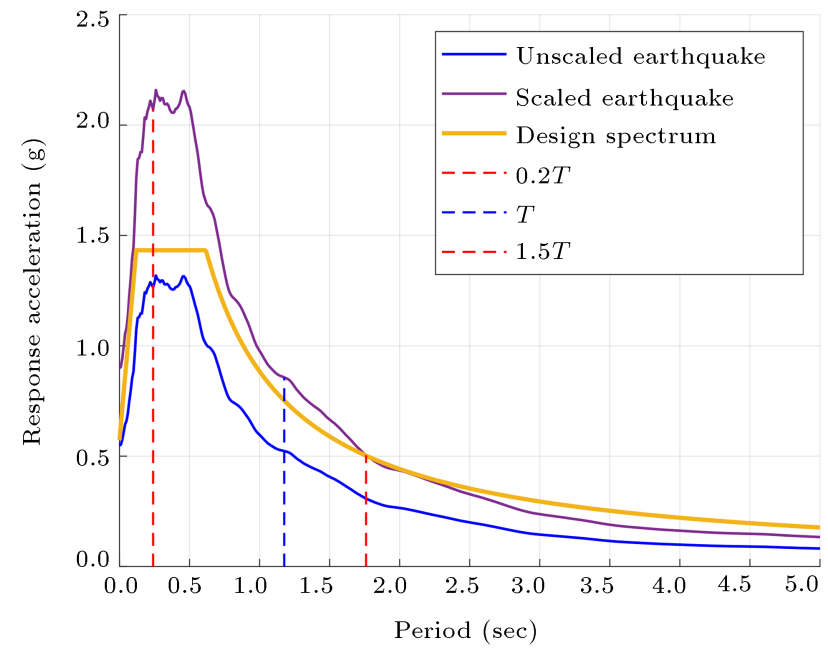

Figure 6. Overview of the procedure of scaling the average of the selected earthquake records.

histories of the control parameters are determined [12]. The names of the selected ETEF series and their brief description are presented in Table 2.

\section{Target times of ETEF series}

The comparison of the structural responses obtained from the analysis of structure subjected to earthquake and ET records is performed within a time window from zero to the target time [13]. The target time 
Table 2. Brief description of the selected Endurance Time Excitation Function (ETEF) series [12].

\begin{tabular}{ccccc}
\hline ETEF series & ETA40g & ETA40h & ETA20in & ETA20jn \\
\hline & ASCE7 for Los & Average spectra of 7 & Average of 20 & ASCE7 for Tehran \\
Design spectrum & Angeles ( $\mathrm{Ss}=1.5 ;$ & records for soil C & records (multiple & seismic \\
& $\mathrm{S} 1=0.6 ; \mathrm{Fa}=1.0 ;$ & FEMA 440 selected & directions) used in & characteristics for soil \\
& $\mathrm{Fv}=1.3 ; \mathrm{TL}=8)$ & by Dr. Tajmir & FEMA 440 for soil type C & type C \\
Number of points & 4096 & 4096 & 2048 & 2048 \\
Sampling frequency & $100 \mathrm{~Hz}$ & $100 \mathrm{~Hz}$ & $100 \mathrm{~Hz}$ & $100 \mathrm{~Hz}$ \\
\hline
\end{tabular}

is when the intensity of the excitation created by the ETEF is equal to the average intensity of the earthquakes. The intensity criterion is usually the intensity of the acceleration spectrum in the range $0.2 T$ to $1.5 T$ [14]. Within this period range, the average intensity of the ETEF spectra should be pursued until it reaches that of the earthquake ground motions at a particular time, which is the target time. This time will be the target time $[15,16]$. In simple terms, the necessary condition for comparing ETEF with ground motion is to determine the target time for each ETEF.

The procedure for determining the target time of ETA $40 \mathrm{~g}$ series records when the structure is under the action of the MUL009 earthquake is shown in Figure 7. As shown in Figure 7, after determining the fundamental period of the studied structure, the spectra of the MUL009 earthquake and ETA40g records in several time windows starting at zero and ending at the target time were derived. It was determined that if the ETA 40 g records target time was equal to 17.47 seconds, the area below their graph of acceleration spectrum would have the least discrepancy in comparison to that of the MUL009 record in a period range starting at $0.2 T$ and ending at $1.5 T$.

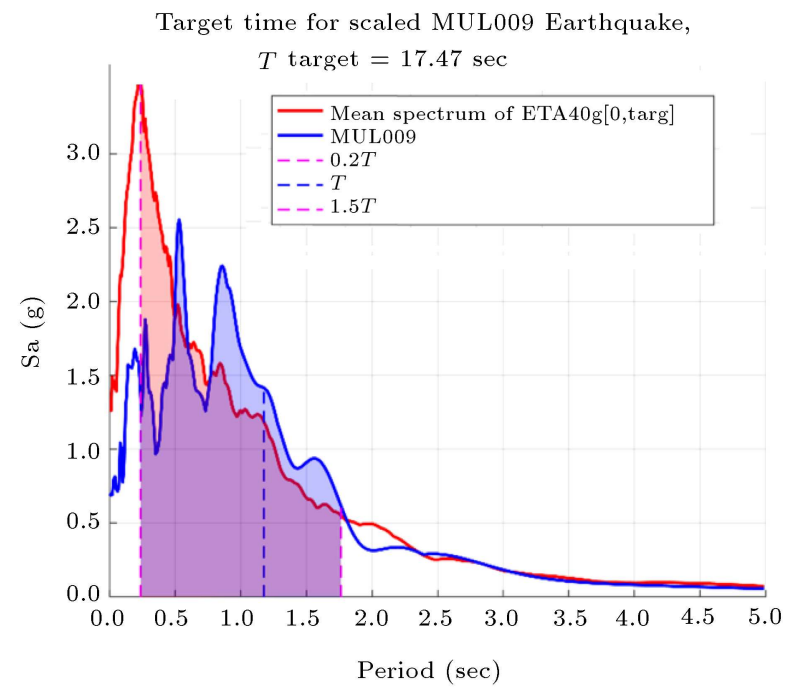

Figure 7. Matching the target time of ETA40g record for MUL009 scaled earthquake record.

\section{Structural responses and performing the comparison}

Table 3 contains the maximum responses of the control parameters of the structure subjected to the scaled ground motions. These results have been obtained from nonlinear time history analysis and will be compared to their corresponding values from ET analysis. For a general comparison, Table 4 is provided which contains the maximum values of the selected control parameters of the structure subjected to ETEFs and ground motions. Its last column contains the average error percentages of each ETEF series, which is used to estimate the responses of the structure subjected to each selected scaled earthquake record. It should be noted that the data in ETEF rows are the average of the three individual records in each series of ETEFs. For a much better illustration of the data provided in the aforementioned table, Figure 8 is provided.

It can also be concluded from Table 4 that ETEFs have high statistical dispersion in estimating the response of the structure under each seismic condition. For instance, ETEFs can estimate the responses in the CAP000 earthquake with an average error percentage of 14 , but in the case of the H-DLT262 earthquake, this parameter is equal to $42 \%$.

It is worth mentioning that every series of ETEFs consists of three single records; for instance, the ETA20inx series contains "ETA20inx01", "ETA20inx02", and "ETA20inx03" records that vary in their excitation functions. Since ET references contend that using merely one or two of these records, results in wrong responses, for obtaining more precise and accurate results, all of them must be imposed to the structure and the maximum of absolute of their response time histories (not the mean or median of them), shall be utilized [17]. However, recently researchers have become more and more interested in the production and utilization of a single ETEF with the help of special mathematical procedures (such as spectral matching methods) [18].

Based on Figure 8, it is apparent that in a few cases, ETEFs have noticeable errors in estimating the results of a few earthquake cases such as the MUL009 earthquake, but on the other hand, there are some 
Table 3. Maximum amounts of the chosen parameters (case: earthquakes).

\begin{tabular}{ccccc}
\hline No. & Earthquakes & $\begin{array}{c}\text { Base shear } \boldsymbol{X} \\
\left(\text { ton }_{\boldsymbol{f}}\right)\end{array}$ & $\begin{array}{c}\text { Roof disp. } \\
(\mathbf{c m})\end{array}$ & $\begin{array}{c}\text { Column C1 force } \\
\left(\text { ton }_{\boldsymbol{f}}\right)\end{array}$ \\
\hline 1 & MUL009 & 5450 & 65 & 27.9 \\
2 & LOS000 & 3470 & 21.1 & 13.9 \\
3 & BOL000 & 6400 & 35 & 23.6 \\
4 & HEC000 & 2730 & 35.3 & 16.5 \\
5 & H-DLT262 & 1990 & 14.9 & 7.7 \\
6 & H-E11140 & 2920 & 16.8 & 10 \\
7 & NIS000 & 4170 & 20.8 & 18 \\
8 & SHI000 & 2460 & 32.3 & 16.3 \\
9 & DZC180 & 2730 & 27 & 19.2 \\
10 & ARC000 & 1440 & 8.6 & 5.1 \\
11 & YER270 & 3080 & 38.2 & 8.4 \\
12 & CLW-LN & 2720 & 16.3 & 22.9 \\
13 & CAP000 & 4470 & 45.1 & 13.9 \\
14 & G03000 & 5470 & 15.7 & 10.8 \\
15 & ABBAR-L & 4850 & 13.5 & 18 \\
16 & B-ICC000 & 3420 & 37.4 & 16.2 \\
17 & B-POE270 & 4900 & 25.4 & 19.6 \\
18 & RIO270 & 3400 & 36.5 & 13.1 \\
19 & CHY101-E & 2780 & 25.9 & 14.6 \\
20 & TCU045-E & 4120 & 16.6 & 10.7 \\
21 & PEL090 & 2360 & 20 & 9.9 \\
22 & A-TMZ000 & 2890 & 14.6 & \\
\hline
\end{tabular}

$$
\mu(\%)=\frac{\text { Value of control parameter } \text { Earthquake }_{\text {Value of control parameter }} \text { ET }}{\text { Value Earthquake }_{\text {Val }}} \times 100
$$

Box I

cases like the ARC000 earthquake that ETEFs have estimated precise structural responses. It is expected that the comparison of these two different cases will lead us to a general conclusion. As it was illustrated in Section 4, the mentioned comparison needs to be done regarding each ET record's target time. Figure 9 has been provided to facilitate the conclusion. It consists of diagrams containing the spectra of the MUL009, ARC000, and ETEFs (until their target times). Within the period range $0.2 T$ to $1.5 T$, a significant difference can be observed between the area under the spectra of the MUL009 and the ETEF. On the other hand, in the case of the ARC000, the mentioned discrepancy is insignificant. Therefore, it can be concluded that this discrepancy is due to the incompatibility between the shape of the ground motion spectrum and the shape of ETEF (until its target time) in the selected period range.

To calculate the mean error percentages of ETEFs in estimating the values of the control parameters, Eq. (1), shown in Box I, has been employed and the results have been compiled in Table 5. It should be noted that the ETA20jn series cannot be utilized in this study due to its disability in estimating the results of 6 earthquake ground motions cases. In other words, the error percentage of this series in Table 5 is the mean of 16 items, not 22 .

By observing the results indicated in Table 5 it can be concluded that the four selected series of ETEFs have significantly different accuracies (26.4\% error on average) in predicting the responses of an intermediate concrete moment frame structure subjected to individual ground motions. To determine the origin of this error, the average of the values of the response acceleration spectra of ETEFs and earthquake records within the period range of $0.2 T$ to $1.5 T$ are compared. Table 6 indicates the mean error percentages of each series of ETEFs spectra and that of earthquake records 


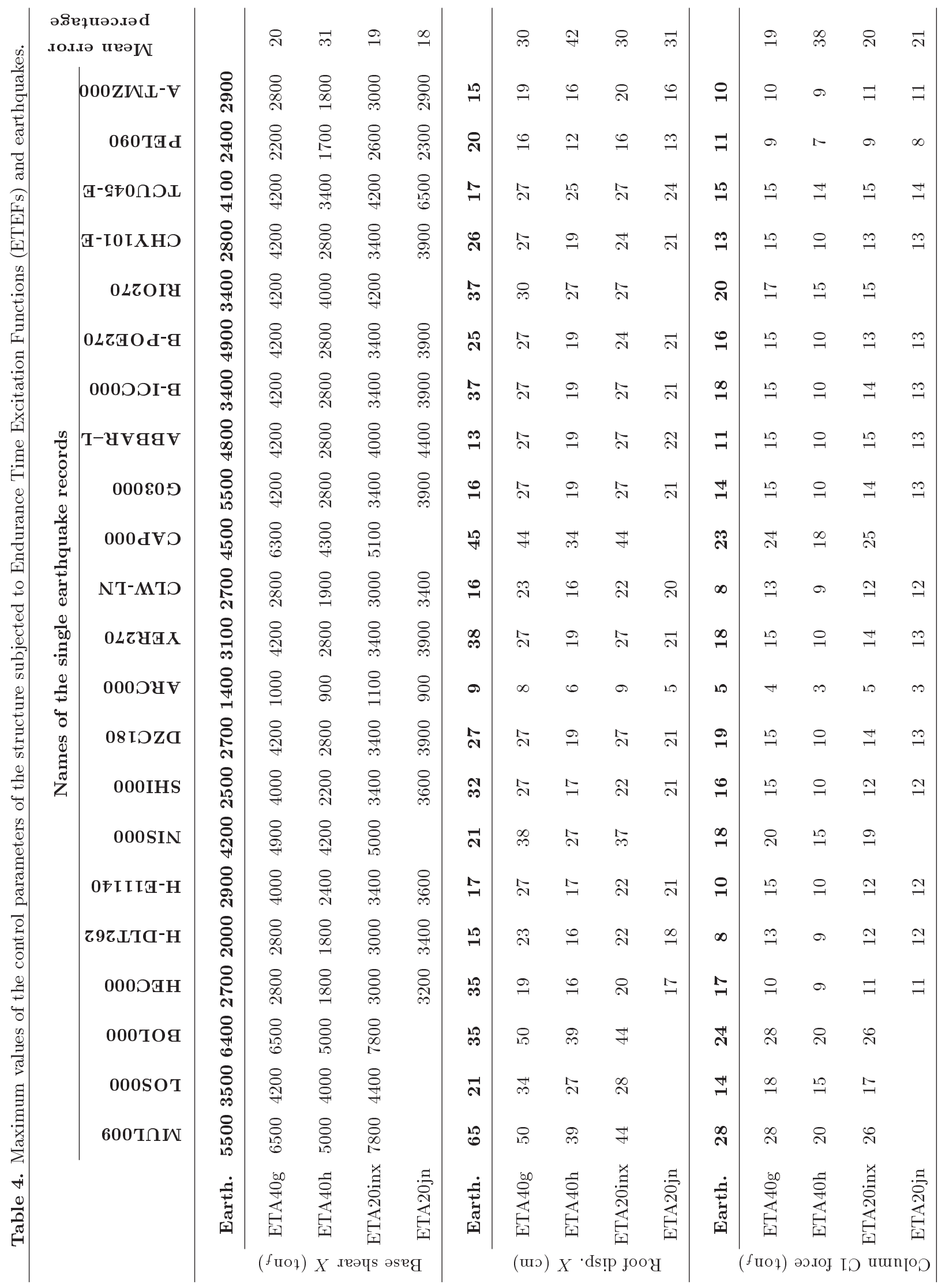



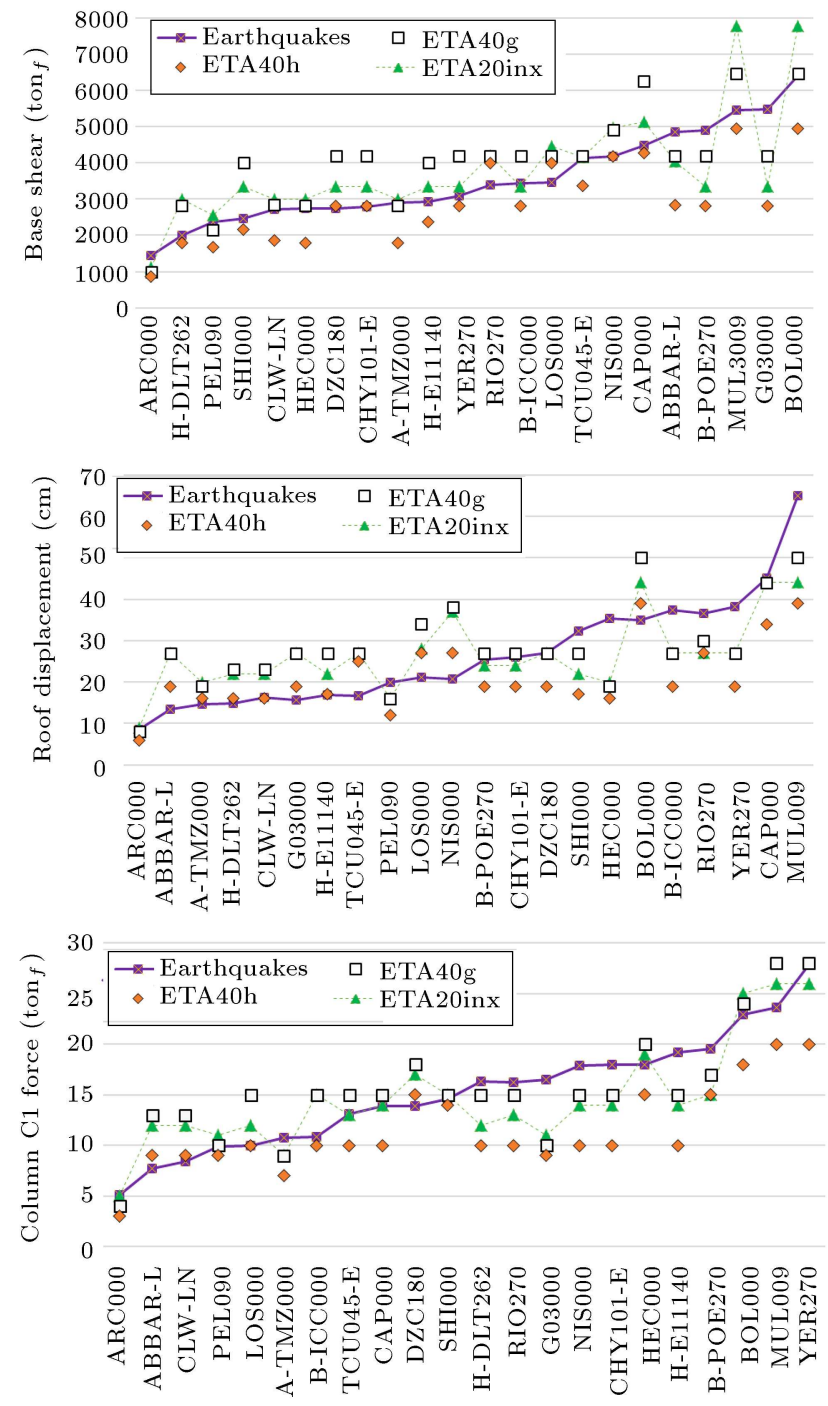

Figure 8. Overview of the values of the control parameters of the structure subjected to Endurance Time Excitation Functions (ETEFs) and ground motions.

inside the mentioned period range. Regarding Tables 5 and 6 , it can be concluded that the ETA20inx series is the most appropriate ETEF series for estimating the responses of the studied structure subjected to the selected scaled earthquake records.

This conclusion is reasonable and can be predicted through the initial steps of the study. For a better

Table 5. Total mean error of the estimated values of the control parameters in comparison to their real values (earthquake results).

\begin{tabular}{cc}
\hline ETA series & Mean error percentage \\
\hline ETA20inx & 24.5 \\
ETA40h & 25.1 \\
ETA40g & 27.2 \\
ETA20jn & 29 \\
\hline
\end{tabular}

understanding, Table 7 is provided, which contains the main attributes of the ETEF series used.

Among these four series of ETEFs, the ETA20inx series have the most common properties with the conditions of our project and the selected earthquake records. For instance, the template spectrum of the mentioned series is very similar to that of our project and the soil type of both is $\mathrm{C}$. In addition, the optimization scope and applicability of this series can also explain why its accuracy in predicting seismic response is higher than other series. Therefore, it can be concluded that selected ETEF series and earthquake records that have the most attributes in common will provide the most similar and compatible analysis results. In fact, it is recommended that researchers produce a specific ETEF for their project to obtain the most precise and accurate results. In [19], for the first time, for time history analysis of a gravity dam, an ETEF has been generated that its response spectra and other intensity characteristics (e.g., nonlinear displacement and hysteretic energy) are compatible with a selected real ground motion.

\section{Conclusions}

The Endurance Time (ET) method is a time history analysis method that simplifies the estimation of structural response at different seismic intensity levels Endurance Time Excitation Functions (ETEFs) play a pivotal role in the performance of the ET method. In the present study, the capability of the existing ETEFs to estimate the response of the structure under a single ground motion was evaluated. The results of the present study could be summarized as follows:

1. Various ETEF series have an average error percentage of 24 to 29 (total mean error of $26 \%$ ) in estimating the responses of intermediate concrete moment frame structure located on soil type $\mathrm{C}$ in Tehran which is subjected to individual ground motions. It is apparent that the responses with such errors are not reliable. However, this conclusion is limited to the analysis of a single ground motion, especially when the acceleration spectrum is not smooth;

2. Error percentage of the conventional ET analysis (using the existing ETEFs) in the estimation of structural responses of various single ground motions may significantly differ from each other. For instance, the existing ETEFs can estimate the structural responses of the CAP000 earthquake with an average error percentage of 14 but in the case of the H-DLT262 earthquake, the latter parameter is equal to $42 \%$. The magnitude of the error mainly depends on the degree of unsmoothness and turbulence of the spectrum of a single ground 

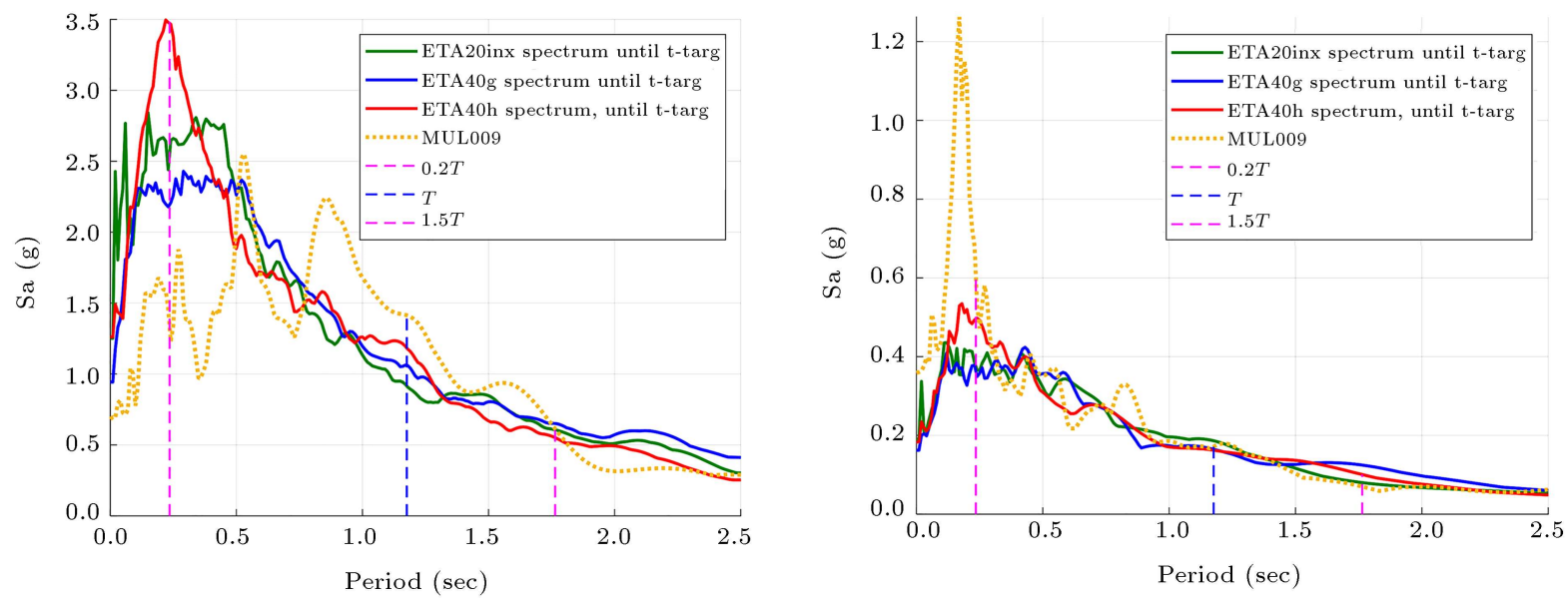

Figure 9. Comparison of the spectra of MUL009 and ARC000 earthquakes with Endurance Time Excitation Function (ETEF) series at their target times.

Table 6. Error percentages of the spectra of Endurance Time Excitation Functions (ETEFs) in comparison to each spectrum of the 22 selected ground motions.

\begin{tabular}{cccc}
\hline Type of ET analysis & \multicolumn{2}{c}{ Error percentages } \\
\cline { 2 - 4 } & ETA20inx & ETA40g & ETA40h \\
\hline $\begin{array}{c}\text { Average error percentage of ETEF spectra in } \\
\text { comparison to the spectrum of each of the } \\
\text { selected earthquake records }\end{array}$ & 30.2 & 88.4 & 88.6 \\
(singular earthquake recorded ET analysis) & & \\
Average error percentage of ETEF spectra in \\
comparison to the spectrum of the average of all \\
of the selected earthquake records \\
$\quad$ (conventional ET analysis)
\end{tabular}

Table 7. Main properties of the selected series of Endurance Time Excitation Functions (ETEFs).

\begin{tabular}{ccccc}
\hline $\begin{array}{c}\text { ETEF } \\
\text { series }\end{array}$ & $\begin{array}{c}\text { Template } \\
\text { spectra }\end{array}$ & $\begin{array}{c}\text { Optimization } \\
\text { scope }\end{array}$ & Applicability & Notes \\
\hline ETA20inx & FEMA440 20 GMs & Nonlinear & Nonlinear & Recommended for general and nonlinear analysis \\
ETA40g & ASCE07 & Linear & Nonlinear & Covers higher intensities up to a scale factor of 4 \\
ETA40h & FEMA440 7 motions & Linear & Nonlinear & Covers higher intensities up to a scale factor of 4 \\
ETA20jn & ASCE07 & Nonlinear & Nonlinear & Design applications \\
\hline
\end{tabular}

motion. Since these fluctuations are smoothed in the conventional ET analysis by using the average of multiple earthquake records, such problems do not arise in that case.

3. In this study, the target time is defined as the equalization time of the spectral mean values of ETEFs and seismic records (within the period range of $0.2 \mathrm{~T}$ to $1.5 \mathrm{~T}$ ). However, various methods for determining the target time do exist and are expected to have a considerable effect on the accuracy of the ET method in estimating the responses of singular earthquakes.

\section{References}

1. Valamanesh, V., Estekanchi, H.E., and Vafai, A. "Characteristics of second-generation endurance time acceleration functions", Scientia Iranica, Transactions A, Civil Engineering, 17(1), pp. 53-61 (2010).

2. Mashayekhi, M., Estekanchi, H.E., and Vafai, A. "Optimal objective function for simulating endurance time excitations", Scientia Iranica, Transactions A, Civil Engineering, 27(4), pp. 1728-1739 (2020).

3. ASCE "Minimum design loads and associated criteria for buildings and other structures, ASCE 7-10", American Society of Civil Engineers (2010). 
4. Building and Housing Research Center (BHRC), Iranian Code of Practice for Seismic Resistant Design of Buildings, Standard No. 2800, 4th Ed.", Tehran, Iran (2016).

5. Computers \& Structures Inc (CSI), CSI Analysis Reference Manual (2019).

6. Federal Emergency Management Agency (FEMA) Quantification of Building Seismic Performance Factors, FEMA P-695, Washington, DC (2009).

7. Pacific Earthquake Engineering Research Center "Pacific Earthquake Engineering Research Center (PEER) ground motion database", Available at: https://ngawest2.berkeley.edu/ (2021).

8. Unified Facilities Criteria, UFC 3-301-01, Department of Defense, United States of America (2019).

9. Riahi, H.T. and Estekanchi, H.E. "Comparison of different methods for selection and scaling of ground motion time histories", 5th International Conference on Seismology and Earthquake Engineering, pp. 13-16 (2007).

10. Shirkhani, A., Azar, B.F., and Basim, M.C. "Optimum slip load of T-shaped friction dampers in steel frames by endurance time method", Proceedings of the Institution of Civil Engineers - Structures and Buildings, 173(10), pp. $746-760$ (2020).

11. Shirkhani, A., Azar, B.F., Basim, M.C., et al. "Numerical methods in civil engineering performance-based optimal distribution of viscous dampers in structure using hysteretic energy compatible endurance time excitations", Journal of Numerical Methods in Civil Engineering, 5(3), pp. 46-55 (2021).

12. Estekanchi, H.E. and Vafai, A.H., Seismic Analysis and Design Using the Endurance Time Method, 2nd Edn., CRC Press, New York, USA (2021).

13. Basim, M., Estekanchi, H.E., and Vafai, A. "A methodology for value based seismic design of structures by the endurance time method", Scientia Iranica, Transaction A, Civil Engineering, 23(6), pp. 25142527 (2016).

14. Bazmooneh, A. and Estekanchi, H.E. "Determination of target time for endurance time method at different seismic hazard levels", Scientia Iranica, Transaction A, Civil Engineering, 25(1), pp. 33-49 (2018).

15. Mashayekhi, M. and Estekanchi, H.E. "Investigation of strong-motion duration consistency in endurance time excitation functions", Scientia Iranica, Transaction A, Civil Engineering, 20(4), pp. 1085-1093 (2013).

16. Ahmadie Amiri, H., Pournamazian Najafabadi, E., Estekanchi, H.E., et al. "Performance-based seismic design and assessment of low-rise steel special moment resisting frames with block slit dampers using endurance time method", Engineering Structures, 224(110955), pp.1-17 (2020).

17. Estekanchi, H.E., Vafai, A., and Basim, M.C. "Design and assessment of seismic resilient structures by the endurance time method", Scientia Iranica, Transaction A, Civil Engineering, 23(4), pp. 1648-1657 (2016).

18. Zhang, R., Zhang, L., Pan, C., et al. "Generating high spectral consistent endurance time excitations by a modified time-domain spectral matching method", Soil Dynamics and Earthquake Engineering, 145(106708), pp. 1-14 (2021).

19. Salamon, J.W., Hariri Ardebili, M.A., Estekanchi, H.E., et al. "Seismic assessment of a dam-foundationreservoir system using endurance time analysis", ICOLD Proceedings Series, 2, pp. 2659-2669 (2019).

\section{Biographies}

Sina Davari was born in 1997. He received his BS and MS degrees in Civil and Structural Engineering from the University of Tabriz and Sharif University of Technology in 2018 and 2020, respectively. He is currently a PhD student in Structural Engineering at the Sharif University of Technology.

Homayoon E. Estekanchi is a Professor of Civil Engineering at the Sharif University of Technology. He received his PhD in Civil Engineering from SUT in 1997 and has been a faculty member at SUT since then. $\mathrm{He}$ is a member of the Iranian Construction Engineers Organization, ASCE, Iranian Inventors Association, and several other professional associations. 